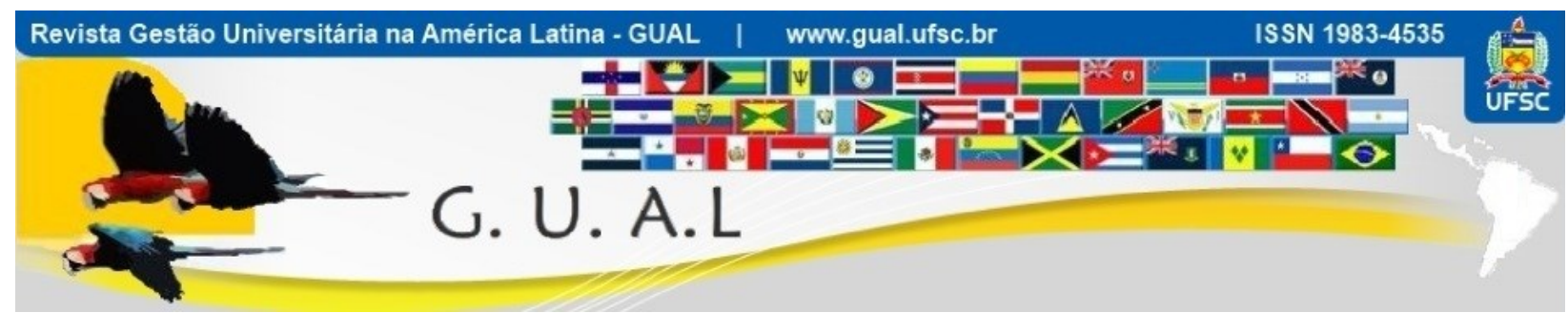

DOI: http://dx.doi.org/10.5007/1983-4535.2018v11n1p116

\title{
AVALIANDO AS PRÁTICAS EXTENSIONISTAS NA UNIVERSIDADE FEDERAL DE VIÇOSA - CAMPUS RIO PARANAÍBA: DAS DIRETRIZES DO FORPROEX ÀS PERCEPÇÕES DE ATORES ENVOLVIDOS
}

EVALUATING THE EXTENSION PRACTICES AT THE FEDERAL UNIVERSITY OF VIÇOSA - RIO PARANAÍBA CAMPUS: FORPROEX GUIDELINES TO

PERCEPTIONS OF ACTORS INVOLVED

Lara Luíza Silva, Bacharel Univerisade Federal de Viçosa - UFV

lara luiza_rpa@hotmail.com

Leonardo Pinheiro Deboçã, Doutor Univerisade Federal de Viçosa - UFV leonardopd@gmail.com

Recebido em 04/setembro/2016

Aprovado em 09/novembro/2017

Sistema de Avaliação: Double Blind Review

Esta obra está sob uma Licença Creative Commons Atribuição-Uso. 


\title{
AVALIANDO AS PRÁTICAS EXTENSIONISTAS NA UNIVERSIDADE FEDERAL DE VIÇOSA - CAMPUS RIO PARANAÍBA: DAS DIRETRIZES DO FORPROEX ÀS PERCEPÇÕES DE ATORES ENVOLVIDOS \\ DOI: http://dx.doi.org/10.5007/1983-4535.2018v11n1p116
}

\section{RESUMO}

A oferta de vagas na educação superior cresceu significativamente no Brasil, principalmente após os anos de 1990, contexto no qual as universidades públicas assumem papel relevante no tocante ao tripé ensino, pesquisa e extensão. O objetivo deste trabalho foi avaliar a percepção de docentes e de empresários sobre as atividades de extensão na Universidade Federal de Viçosa - Campus de Rio Paranaíba, em Minas Gerais, Brasil. A avaliação teve como parâmetros as diretrizes para ações de extensão universitária propostas pelo FORPROEX (Fórum de Pró-Reitores de Extensão das Universidades Públicas Brasileiras) pactuadas em 2012. A pesquisa teve caráter quantitativo e qualitativo, objetivando descrever o perfil dos respondentes (15 docentes e 20 empresários) e o significado da extensão para os mesmos, bem como, a conformidade das atividades de extensão com os objetivos do FORPROEX. A mensuração das diretrizes foi pautada em uma escala likert de 1 a 7 pontos. Quanto aos resultados, destaca-se que apenas para a diretriz Indissociabilidade Ensino-Pesquisa-Extensão ocorreram diferenças significativas das médias entre docentes e empresários. A diretriz Impacto e Transformação Social foi a de menor desempenho na avaliação dos empresários, enquanto a de maior desempenho foi a Indissociabilidade Ensino-PesquisaExtensão, também na avaliação dos empresários. Dentre as contribuições deste trabalho, destacase a possível utilização dos resultados para a avaliação de ações, políticas e diretrizes, relativas às atividades de extensão, praticadas pela Universidade, visando melhor alinhamento de interesses e expectativas entre Universidade e comunidade local.

Palavras-chave: Forproex. Extensão Universitária. Universidade.

\begin{abstract}
The education offering have grown significantly in Brazil, especially after the 90's. At this context, public universities assume an important role regarding the support tripod teaching, research and extension. The objective of this paper was to evaluate the perception of teachers and entrepreneurs about the extension activities in Federal University of Viçosa - Rio Paranaíba Campus, Minas Gerais, Brazil. The evaluation had as parameters the guidelines for university extension actions proposed by FORPROEX (Brazilian Public Universities Extension Pro-Rectors Forum) agreed in 2012. The research was quantitative and qualitative, aiming to describe the profile of the respondents ( 15 teachers and 20 entrepreneurs) and the significance of extension for them, as well as the compliance of extension activities with the objectives of FORPROEX. The guidelines measurement was based on a Likert scale of 1 to 7 points. About the results, is important to note that only in the guideline Inseparability Teaching-Research-Extension occurred significant differences of averages between teachers and entrepreneurs, but, for the others it was not observed the same behavior. The guideline Impact and Social Transformation was the one with the lowest performance in the entrepreneurs evaluation, while the one presented the higher performance was the Inseparability Teaching-Research-Extension, also in the evaluation of entrepreneurs. Among the contributions of this paper, it should be highlighted the results for the evaluation of actions, policies and guidelines relating to extension activities, practiced by the University, to a better alignment of interests and expectations between the University and the local community.
\end{abstract}

Keywords: Forproex. University Extension. University. 


\section{AVALIANDO AS PRÁTICAS EXTENSIONISTAS NA UNIVERSIDADE FEDERAL DE VIÇOSA - CAMPUS RIO PARANAÍBA: DAS DIRETRIZES DO FORPROEX ÀS PERCEPÇÕES DE ATORES \\ DOI: http://dx.doi.org/10.5007/1983-4535.2018v11n1p116}

\section{INTRODUÇÃO}

O acesso ao ensino e a oferta de educação tem crescido significativamente nos últimos anos no Brasil, principalmente após os anos 1990. A expansão das redes federais de ensino superior que atende ao Plano Nacional de Educação (PNE) - Lei No 10.172/2001 tem início sobretudo em 2013, quando ocorre o incentivo à interiorização/regionalização dos campi das Universidades Federais (COCCO et al., 2013).

Tal fenômeno pode levar à expectativa de que as universidades desempenhem funções importantes nos locais onde se inserem, e de outro lado, as comunidades locais também devem usufruir da atuação universitária, especialmente tratando-se da extensão universitária.

Neste sentido, Jezine (2004, p.3) afirma:

Os princípios da integração ensino-pesquisa, teoria e prática que embasam a concepção de extensão como função acadêmica da universidade revelam um novo pensar e fazer, que se consubstancia em uma postura de organização e intervenção na realidade, em que a comunidade deixa de ser passiva no recebimento das informações/conhecimentos transmitidos pela universidade e passa a ser participativa, crítica e construtora dos possíveis modos de organização e cidadania.

Diante disso, é importante o despertar da universidade para a comunidade no sentido de perceber as demandas por ela emanadas e necessidades a serem supridas. De forma semelhante, é verossímil o despertar da comunidade para os benefícios da ação de ensino, pesquisa e extensão partilhados pela universidade a fim de propiciar o conhecimento e crescimentos sólidos e contínuos.

Nesse sentido, Chauí (2003 n.p.) aponta que “a Universidade é uma instituição social e como tal exprime de maneira determinada a estrutura e o modo de funcionamento da sociedade como um todo".

Ao observar-se a missão das Universidades Públicas depreende-se que, de fato, ela revela de modo peculiar as características da sociedade na qual está inserida, seja por sua postura de dialogicidade com a mesma e também porque esta deve lhe servir de referência em suas necessidades e anseios:

A missão da universidade pública é, antes de qualquer coisa, o compromisso com a produção do conhecimento público, orientado às necessidades populares. A postura dialógica, por outro lado, além de estar em consonância com esse fim, promove o enriquecimento do conhecimento produzido - através da troca entre saberes populares e acadêmicos e da não dissociação entre teoria e prática - e contribui para a ampliação da formação de uma cultura política democrática, através da experiência concreta. (DEPIERI et al., 2010, p.70 apud BARBOSA , 2012, p. 22) 
Desta forma, fica claro que a universidade é um espaço que permite, através de trocas com a sociedade, a complementaridade com o ensino e a pesquisa.

Em conformidade, Nogueira (2005) expressa que o papel da universidade sempre passa pela extensão, motivo pelo qual as IES (Instituições de Ensino Superior) podem cumprir seu compromisso social, avançando além de suas atividades relacionadas à sua atividade- fim por meio de cursos regulares.

Portanto, sem a interação dialógica possibilitada pelas atividades extensionistas, a Universidade corre o risco de ficar isolada, ensimesmada, descolada dos problemas sociais mais prementes e incapaz de oferecer à sociedade e aos governos o conhecimento, as inovações tecnológicas e os profissionais que o desenvolvimento requer. (FORPROEX, 2012).

Neste contexto, com o presente trabalho, buscamos responder à seguinte questão: De um lado, como o corpo docente do Instituto de Ciências Humanas e Sociais (ICHS) da Universidade Federal de Viçosa - Campus de Rio Paranaíba (UFV-CRP) define a extensão desempenhada na cidade de Rio Paranaíba, e, de outro lado, como os empresários locais percebem as atividades de extensão da UFV-CRP nesta cidade?

A relevância deste trabalho consiste no fato de que uma das expressões notáveis da Universidade se manifesta na extensão do conhecimento para a comunidade e na utilização deste para a modificação do ambiente em que estão inseridos. Portanto, a mesma deve ser mais do que um laboratório, objeto de estudos ou campo de pesquisas, mas também uma instituição com pessoas, demandas, reivindicações, anseios e saberes que se encontram dentro e fora da universidade (NUNES E SILVA, 2011).

\section{FUNDAMENTAÇÃO TEÓRICA}

\subsection{SIGNIFICADOS DE EXTENSÃO}

Não existe apenas uma definição para o termo extensão. Diversos autores e fóruns discutem conceituações para a mesma. O FORPROEX (2012, p.15) assim conceitua:

A extensão universitária, sob o princípio constitucional da indissociabilidade entre ensino, pesquisa e extensão, é um processo interdisciplinar, educativo, cultural, científico e político que promove a interação transformadora entre universidade e outros setores da sociedade. 
Nunes e Silva (2011, p.124) pontuam que:

... a ideia de extensão está associada à crença de que o conhecimento gerado pelas instituições de pesquisa deve necessariamente possuir intenções de transformar a realidade social, intervindo em suas deficiências e não se limitando apenas à formação dos alunos regulares da instituição. De fato, a preocupação das universidades deve ser de formar cidadãos para atuarem no mundo.

Conforme Thiollent (2002, p.2) o conceito de extensão também está intimamente ligado à identificação de problemas e proposição de soluções para comunidade local, numa forma de interlocução com a mesma, conforme os escritos abaixo:

...a extensão também é uma construção ou (re)construção de conhecimento, envolvendo, além dos universitários, atores e públicos com culturas, interesses, níveis de educação diferenciados. A construção extensionista não está limitada aos pares, abrange uma grande diversidade de públicos externos com os quais é preciso estabelecer uma interlocução para identificar problemas, informar, capacitar e propor soluções.

Freire (1985) questiona o termo extensão, alegando que a universidade é um espaço de reflexão e não desempenha o papel de impor, apontando neste caso o termo comunicação como sendo o mais pertinente. Assim sendo, entende que o conhecimento não deve se estabelecer de maneira verticalizada, ou seja, dos que parecem saber mais para os que não sabem ou sabem menos. O trecho abaixo é esclarecedor desta visão:

O conhecimento não se estende do que se julga sabedor até aqueles que se julga não saberem; o conhecimento se constitui nas relações homem-mundo, relações de transformação, e se aperfeiçoa na problematização crítica destas relações (FREIRE, 1985, p.22).

Em relação a esta problemática, Serrano [s.d], baseada nas ideias de Freire, mostra que, em um primeiro momento, a extensão esteve vinculada à transmissão vertical do conhecimento. Segundo a mesma, alguns autores consideram que as escolas gregas foram pioneiras neste processo por abrirem oportunidade de aulas ao público. Entretanto, estas escolas eram abertas a poucas pessoas e eram dotadas de um conhecimento que pouco transformava a realidade.

Assim sendo, nesta lógica de conhecimento, segundo o pensamento freiriano a prática de extensão não se manifesta de maneira plena, mas como um processo verticalizado que "coisifica" o homem, que o faz sujeito passivo no processo. O autor inclusive entende que "transformando o homem em quase "coisa" o negam como um ser de transformação do mundo", para ele se isso acontece a extensão se torna antidialógica e manipuladora (FREIRE, 1985). Portanto, este primeiro momento é marcado por traços autoritaristas da universidade 
para com a sociedade, onde a cultura e saber popular não eram relevantes e apenas a mesma possuía o saber absoluto e superior.

No segundo momento, rompendo-se com a visão da extensão verticalizada, acontecem então experiências da extensão vinculadas à Igreja, partindo de ações educativas e também por uma interface com o movimento iluminista, assumindo o caráter de ação revolucionária. (ROCHA, 2001 apud SERRANO [s.d]).

Entende-se que na passagem do primeiro para o segundo momento, rompe-se então, na visão freiriana com a verticalização do conhecimento, abrindo, através do Movimento Estudantil, uma oportunidade de dialogar através da extensão universitária, ou seja, de reconhecer a capacidade do outro em construir relações com os outros e com o mundo.

Portanto, a verticalidade é trocada pelo início de uma horizontalidade, onde se respeita o sujeito com sua cultura e saber e reconhece-o como importante no processo de transformação da realidade.

Ainda nos anos 60, as ideias de Paulo Freire foram importantes na redefinição da Universidade e da Extensão Universitária. Apesar de terem sido fortemente coibidas pelo regime militar elas serviram como "pano de fundo" para as atividades de extensão desenvolvidas, conforme aponta o escrito abaixo

\begin{abstract}
No Ministério da Educação, o grupo que ocupava a Coordenação das atividades de extensão - CODAE tinha Freire como referência central, o que pode ser mais bem evidenciado na análise do Plano de Ação lançado em 1973. Falava-se em retroalimentação, mão dupla, retroalimentação e outras terminologias similares que, na realidade, propiciaram a incorporação do sentido de comunicação ao extensionismo. (ROCHA, 2001 apud SERRANO, [s.d], p.9).
\end{abstract}

Sendo assim, as ideias deste autor foram precursoras do conceito importante de universidade como visão de trocas, de diálogo, de via de mão dupla, entre outros e contribuíram para uma nova institucionalização da Extensão nos anos de 1980.

Neste momento Extensão adquire novo caráter e assume nova postura frente aos desafios da sociedade que lhe circunda. Este novo revestimento aproxima-se do que vivemos hoje e traz consigo traços de uma extensão universitária democrática, que viabiliza, instrumentaliza o processo dialético teoria/ prática e que carrega em sua forma interdisciplinar a oportunidade de uma visão ampla, integrada e coesa da realidade social. (Serrano, [s.d])

Apreende-se então que a extensão perpassa por dois momentos básicos: 
Quadro 1 Definições conceituais da extensão

\begin{tabular}{|c|c|}
\hline DEFINIÇÃO & CONCEITO \\
\hline $\begin{array}{c}\text { Via de mão única (Processo } \\
\text { Verticalizado e Dirigido) }\end{array}$ & $\begin{array}{c}\text { A universidade “sabedora" vai até a sociedade levar algo da qual é especialista. } \\
\text { Neste caso, a comunidade local é apenas uma receptora do conhecimento. }\end{array}$ \\
\hline $\begin{array}{c}\text { Via de mão dupla (Processo } \\
\text { Horizontalizado e } \\
\text { Democrático) }\end{array}$ & $\begin{array}{c}\text { A universidade dialoga com a sociedade, viabilizando a troca de saberes, } \\
\text { respeitando os sujeitos e sua cultura e percebendo-os como importantes no } \\
\text { processo de transformação da realidade social. }\end{array}$ \\
\hline
\end{tabular}

Fonte: Elaborado pelos autores (2015).

Ainda em relação a extensão, foram elaboradas diretrizes que servem como orientadoras destas atividades, dando suporte à formulação e implementação das ações de extensão para as Universidades.

\subsection{DIRETRIZES PARA AÇÕES DE EXTENSÃO UNIVERSITÁRIA}

Diretrizes fazem alusão à normas ou caminhos para que se alcancem objetivos propostos. De forma semelhante, as diretrizes do FORPROEX são norteadoras para as práticas universitárias extensionistas. Segundo o fórum e de acordo com Nogueira (2000) elas são: Interação Dialógica, Interdisciplinaridade e Interprofissionalidade, Indissociabilidade Ensino-Pesquisa-Extensão, Impacto na Formação do Estudante e Impacto e Transformação Social. Portanto, baseado no FORPROEX (2012) elas são:

Interação Dialógica: esta diretriz busca estabelecer o diálogo e a troca de saber entre as Universidades e os setores sociais, vencendo os limites do discurso da hegemonia acadêmica e trocando por ideias com estes movimentos e setores sociais. Neste caso, o conhecimento acumulado não será "estendido" à comunidade através da Universidade, ao contrário disso, haverá a interação e produção conjunta de um novo conhecimento, conhecimento este, que seja capaz de atenuar as desigualdades e exclusões sociais e cooperar na construção de uma sociedade justa, ética e democrática. Além disso, é necessária a apropriação e democratização da autoria dos atores sociais, de modo semelhante, é importante sua participação nos eventos e ações desenvolvidos na Universidade. Neste caso, a interação dialógica é uma diretriz relevante em virtude de estar no campo das relações, atingindo o âmago da dimensão ética dos processos de Extensão Universitária. Neste sentido entende-se:

Isto é, o diálogo é uma espécie de postura necessária, na medida em que os seres humanos se transformam cada vez mais em seres criticamente comunicativos. O diálogo é o momento em que os humanos se encontram para refletir sobre sua realidade tal como a fazem e re-fazem. [...] O que é o diálogo, neste momento de comunicação, de conhecimento e de transformação social? $\mathrm{O}$ diálogo sela o 


\title{
AVALIANDO AS PRÁTICAS EXTENSIONISTAS NA UNIVERSIDADE FEDERAL DE VIÇOSA - CAMPUS RIO PARANAÍBA: DAS DIRETRIZES DO FORPROEX ÀS PERCEPÇÕES DE ATORES ENVOLVIDOS \\ DOI: http://dx.doi.org/10.5007/1983-4535.2018v11n1p116
}

\begin{abstract}
relacionamento entre os sujeitos cognitivos, podemos, a seguir, atuar criticamente para transformar a realidade (FREIRE \& SHOR, 1987, p.64).

Interdisciplinaridade e Interprofissionalidade: segundo o FORPROEX (2012) durante
\end{abstract} muito tempo as tecnologias de intervenção social oscilaram entre visões holistas voltadas para apreender a complexidade do todo porém tendenciosas ao generalismo e de outro lado visões especializadas, que buscavam tratar especificidades e ao mesmo tempo culminavam num parcelamento do todo. Portanto, esta diretriz busca superar esta dicotomia numa tentativa de combinar a especialização e também considerar a complexidade das comunidades, setores e grupos sociais nos quais são desenvolvidas as ações extensionistas. Portanto, ainda segundo o Fórum, a intenção desta diretriz é que a combinação de especialização e visão holista se materialize na interação de modelos, conceitos e metodologias advindos de várias disciplinas e áreas do conhecimento, construindo alianças intersetoriais, interorganizacionais e interprofissionais. Aí então, serão impressas nas ações de extensão a consistência teórica e operacional da qual depende sua efetividade. Em complemento a esta visão, Frigotto (1976) aponta que a interdisciplinaridade não está em oposição aos conhecimentos especializados, mas corrobora com o entendimento e compreensão da multiplicidade de elementos da realidade que compõe a totalidade. Leff (2000) entende que ela é a cooperação recíproca entre várias disciplinas ao propiciar um intercâmbio real e resultar em enriquecimentos mútuos alcançados por meio de uma estratégia que busca a união de diferentes disciplinas para tratar de um problema comum.

Indissociabilidade Ensino-Pesquisa-Extensão: ainda segundo o Fórum, esta diretriz reafirma a extensão universitária como processo acadêmico. Neste caso, as ações de extensão serão dotadas de maior efetividade quanto mais se vincularem ao processo de formação de pessoas (Ensino) e geração de conhecimento (Pesquisa). Neste sentido, os estudantes, em sua formação técnica, adquirem papel importante por obter competências necessárias à atuação profissional e também por sua formação cidadã ao ser reconhecido como um agente de garantia de direitos, deveres e transformação social. Ressalte-se ainda que o protagonismo dos estudantes estende-se também a todos os envolvidos nas ações de Extensão Universitária, sejam eles alunos, professores, técnicos-administrativos, pessoas da comunidade, dentre outros. Então, a partir daí, um novo conceito de sala de aula pode ser formulado, compreendendo-se que a sala de aula são todos os espaços, dentro e fora da universidade, em que se aprende e se (re)constrói o processo histórico-social em suas múltiplas determinações e facetas, então o eixo clássico estudante-professor é substituído pelo eixo estudante-professor- 


\section{AVALIANDO AS PRÁTICAS EXTENSIONISTAS NA UNIVERSIDADE FEDERAL DE VIÇOSA - CAMPUS RIO PARANAÍBA: DAS DIRETRIZES DO FORPROEX ÀS PERCEPÇÕES DE ATORES ENVOLVIDOS \\ DOI: http://dx.doi.org/10.5007/1983-4535.2018v11n1p116}

comunidade. Então, o estudante passa a ser um agente que contribui para o crescimento sendo aportado pelo conhecimento adquirido, apontado as direções para este processo. Segundo Moita e Andrade (2009), conscientes das particularidades que caracterizam cada uma das três funções universitárias, entende-se que esta indissociabilidade como um catalisador do conhecimento "pluriversitário". Ainda segundo os mesmos, a extensão não deve ser tratada como uma tarefa compulsória, mas sim como uma atividade semelhante à pesquisa, que decorre naturalmente do compromisso social de uma instituição que é orientada pela superação das distâncias entre os saberes científico e popular.

Assim, este tripé se torna uma referência para que o ensino não se torne abstrato e nem desligado das realidades locais. Estes autores ressaltam ainda que, outra vantagem da indissociabilidade consiste no fato de que nem toda pesquisa consiste em extensão, pois pode ser que o conhecimento produzido seja encarcerado no debate teórico ou desenvolvido com objetivos que não sejam de atender as populações participantes da investigação; e de outro lado, se a extensão for orientada pelos princípios da superioridade do saber científico em relação ao saberes dos grupos atendidos não será plena em seus objetivos. Então, somente ela poderá garantir a integração desses saberes com a ciência e concomitantemente a permanente articulação entre os três eixos. Em complemento aos autores, Castro (2004) pontua que a extensão:

\footnotetext{
...se coloca como um espaço estratégico para promover práticas integradas entre as várias áreas do conhecimento. Para isso é necessário criar mecanismos que favoreçam a aproximação de diferentes sujeitos, favorecendo a multidisciplinaridade; potencializa, através do contato de vários indivíduos, o desenvolvimento de uma consciência cidadã e humana, e assim a formação de sujeitos de mudança, capazes de se colocar no mundo com uma postura mais ativa e crítica. A extensão trabalha no sentido de transformação social. (CASTRO, 2004, p.13)
}

Impacto na formação do estudante: segundo o FORPROEX (2012) as atividades de extensão constituem fatores decisivos à formação do estudante, seja por ampliar o universo de referência que os mesmos ensejam ou pelo contato direto com as questões contemporâneas. Ainda segundo o mesmo, esses resultados são enriquecedores ao mesmo tempo em que abrem espaços para a reafirmação e materialização dos compromissos éticos e solidários da Universidade Pública Brasileira. Aponta ainda que a qualificação da formação do estudante através das atividades extensionistas depende também de um diálogo franco e permanente dos órgãos destinados ao fomento das ações extensionistas como os colegiados de gestão 
acadêmica da graduação de forma a possibilitar a aplicação efetiva das de todas as diretrizes de Extensão Universitária e da legislação vigente.

Impacto e Transformação Social: neste caso compreende-se que a extensão reafirma o mecanismo de inter-relação da universidade com os demais setores da sociedade com vistas à atuação transformadora, voltada para interesses e demandas da maioria da população e causadora de desenvolvimento social e regional como também aprimoramento de políticas públicas. Desta forma, segundo o FORPROEX (2012) através desta diretriz espera-se conquistar: (i) privilegiamento de questões sobre as quais se deve atuar sem desconsiderar a complexidade e diversidade da realidade social; (ii) abrangência de forma que a ação ou seu conjunto possa ser suficiente para ofertar contribuições relevantes na transformação da área, setor ou comunidade sobre os quais se atua e (iii) efetividade na solução de problemas. Algo importante a ser considerado é que não é apenas na sociedade que se vislumbra conseguir impacto, mas também a própria Universidade Pública pode desfrutar de mudanças e transformações, considerando que a implementação de todas as demais diretrizes anteriormente citadas é imprescindível para tal.

\section{PROCEDIMENTOS METODOLÓGICOS}

Para alcançar os objetivos de avaliar a percepção dos empresários e professores acerca da extensão desenvolvida pela UFV-CRP utilizou-se a metodologia de pesquisa descritiva. Segundo Vergara (2006), neste tipo de trabalho, as variáveis são observáveis, mas não manipuláveis, assim sendo, é possível descrever as características de determinada população ou fenômeno, buscando ampliar o conhecimento e não generalizá-lo.

A pesquisa também se caracterizou por uma abordagem quanti-qualitativa. Gomes e Araújo (2005) expressam que na área de administração há um contexto favorável à utilização de metodologias de pesquisa que adotem um enfoque múltiplo, pois o cenário organizacional é complexo e mutante. Se estudar o ser humano isoladamente já é uma tarefa desafiadora, entende-lo no ambiente organizacional é uma tarefa ainda mais intensa.

O local estudado se delimitou à cidade de Rio Paranaíba, a qual está localizada na região do Alto Paranaíba, estado de Minas Gerais. Segundo dados do IBGE (Instituto Brasileiro de Geografia e Estatística) em 2013, o município em questão contava com uma população estimada de 12.328 habitantes. O total de empresas atuantes em 2012 era de 261 unidades. As principais atividades desenvolvidas estão delineadas em agricultura e pecuária, 
com destaque para produção de café, milho, soja, cenoura, batata, cebola, alho e outros em menor escala.

A pesquisa foi realizada com os docentes da UFV-CRP, especificamente com 15 professores do Instituto de Ciências Humanas e Sociais (ICHS) e com 20 empresários de Rio Paranaíba. A escolha destes empresários foi não probabilística por conveniência, referenciada em empresas associadas na ACIARP (Associação Comercial, Industrial e Agropecuária de Rio Paranaíba) fundada em 14 de março de 1986 e também nas empresas citadas pelos docentes como participantes ou convidadas até então para projetos extensionistas praticados pela universidade. Ressalta-se que o estudo foi realizado com tantas empresas quantas foram possíveis ou estiveram disponíveis e interessadas em participar da pesquisa.

Para coleta de dados, utilizou-se o questionário, sendo este dotado de perguntas objetivas e subjetivas. Sobre os questionários, Richardson (1999) afirma que estes cumprem pelo menos duas funções: descrever características e medir variáveis de grupos sociais. Como vantagens de se aplicar questionários pode-se citar a possibilidade de se obter informações de grande número de pessoas em tempo curto e abranger área geográfica ampla. Ressalta ainda que a técnica apresenta uniformidade, devido ao vocabulário, à ordem das perguntas e às instruções iguais para os entrevistados e que o questionário poderá ser anônimo para que as pessoas tenham maior liberdade de expressar suas opiniões.

Os dados objetivos dos questionários foram tabulados e submetidos à análise estatística no software SPSS 19.0 ® (Statistical Package for the Social Sciences). A análise dos mesmos foi pautada no Teste $\mathrm{T}$ de Student para amostras independentes, o qual objetiva verificar se existem diferenças significativas entre as médias estudadas. Desta forma, estabeleceu-se um intervalo de confiança de $95 \%$, o que implica em um $\alpha=0,05$.

Os dados subjetivos foram observados seguindo o critério de análise de conteúdo, onde as perguntas foram gravadas e transcritas, nomeando-se os docentes com o código " $\mathrm{D}$ " e os empresários com o código "E". O objetivo dos dados subjetivos é justamente o de permitir a expressão da percepção tanto dos professores, quanto dos empresários acerca da avaliação da manifestação da extensão da Universidade para a Comunidade.

Alguns dados objetivos foram pautados no método de Escalas Likert, as quais conforme Cunha (2007) são compostas por um conjunto de frases (itens) em relação a cada uma das quais se pedem ao sujeito que está a ser avaliado para manifestar o grau de 


\section{AVALIANDO AS PRÁTICAS EXTENSIONISTAS NA UNIVERSIDADE FEDERAL DE VIÇOSA - CAMPUS RIO PARANAÍBA: DAS DIRETRIZES DO FORPROEX ÀS PERCEPÇÕES DE ATORES ENVOLVIDOS \\ DOI: http://dx.doi.org/10.5007/1983-4535.2018v11n1p116}

concordância desde o discordo totalmente (nível 1), até ao concordo totalmente (nível 5, 7 ou 11), neste caso, a escala adotada foi a de 7 pontos.

Em relação à definição do que são as atividades extensionistas descritas nos questionários utilizou-se o critério de definição proposto pelo RAEX (Registro de Atividades de Extensão) da UFV, elencadas a seguir: programa, projeto, curso, evento, prestação de serviço, atividade acadêmica de extensão externa e, ou interna, museu e espaço de ciência e tecnologia.

A fim de evidenciar a percepção dos docentes do ICHS e dos empresários de Rio Paranaíba foram elaboradas 10 afirmações no questionário pautadas em escala likert de 7 pontos, onde eles possuíam as opções discordo totalmente (1), discordo (2), discordo parcialmente (3), não concordo e nem discordo (4), concordo parcialmente (5), concordo (6), concordo totalmente (7) com relação a cada assertiva. Foram realizadas duas afirmações relacionadas à cada diretriz pactuada pelo Forproex (2012), conforme observa-se:

Quadro 2 Diretrizes pactuadas pelo Forproex e Questões Propostas no Questionário

\begin{tabular}{|c|c|}
\hline DIRETRIZ & AFIRMAÇÃO \\
\hline Interação Dialógica & $\begin{array}{l}\text { As atividades são praticadas enfatizando a troca de conhecimentos entre a } \\
\text { Universidade e a comunidade local, ou seja, há uma troca de saberes, e não } \\
\text { uma postura em que o conhecimento vem somente da Universidade. }\end{array}$ \\
\hline Interação Dialógica & $\begin{array}{l}\text { As atividades de extensão mostram que a UFV está sempre aberta a } \\
\text { relacionar com os diversos setores da comunidade local, principalmente } \\
\text { porque utiliza metodologias que estimulam a participação da comunidade. }\end{array}$ \\
\hline $\begin{array}{l}\text { Interdisciplinaridade e } \\
\text { Interprofissionalidade }\end{array}$ & $\begin{array}{l}\text { Propõem soluções com abordagens que consideram o envolvimento de } \\
\text { diferentes profissionais, incluindo várias áreas do conhecimento, ao invés de } \\
\text { uma postura que utiliza conhecimentos profissionais isolados. }\end{array}$ \\
\hline $\begin{array}{l}\text { Interdisciplinaridade e } \\
\text { Interprofissionalidade }\end{array}$ & $\begin{array}{l}\text { Propõem soluções com abordagens que considerem o envolvimento de } \\
\text { diferentes setores da comunidade ao invés de tratar setores isoladamente, ou } \\
\text { seja, as ações alcançam públicos gerais ao invés de públicos específicos. }\end{array}$ \\
\hline $\begin{array}{l}\text { Indissociabilidade } \\
\text { Pesquisa-Extensão }\end{array}$ & $\begin{array}{l}\text { Estão vinculadas a atividades de Ensino (formação de pessoas) e de } \\
\text { Pesquisa (geração de conhecimento) desempenhadas pelos professores, ao } \\
\text { invés de se apresentarem como atividades isoladas. }\end{array}$ \\
\hline $\begin{array}{l}\text { Indissociabilidade } \\
\text { Pesquisa-Extensão }\end{array}$ & $\begin{array}{l}\text { As atividades reforçam o papel dos estudantes na comunidade promovendo } \\
\text { sua formação como profissional e como cidadão. }\end{array}$ \\
\hline $\begin{array}{l}\text { Impacto na Formação do } \\
\text { Estudante }\end{array}$ & $\begin{array}{l}\text { Envolvem figura de professores orientadores e de estudantes orientados, e } \\
\text { apresentam clareza nos objetivos propostos. }\end{array}$ \\
\hline $\begin{array}{l}\text { Impacto na Formação do } \\
\text { Estudante }\end{array}$ & $\begin{array}{l}\text { Os estudantes têm conseguido desempenhar bem seu papel como agente de } \\
\text { transformação da sociedade, aplicando os conhecimentos adquiridos. }\end{array}$ \\
\hline $\begin{array}{l}\text { Impacto e Transformação } \\
\text { Social }\end{array}$ & $\begin{array}{l}\text { Conseguem apresentar contribuições significativas de mudanças na } \\
\text { comunidade local, produzindo soluções efetivas na resolução de problemas. }\end{array}$ \\
\hline $\begin{array}{l}\text { Impacto e Transformação } \\
\text { Social }\end{array}$ & $\begin{array}{l}\text { Promovem mudanças na Universidade, na medida em que ela se envolve } \\
\text { com a comunidade local. }\end{array}$ \\
\hline
\end{tabular}

Fonte: Elaborado pelos autores (2015). 


\section{AVALIANDO AS PRÁTICAS EXTENSIONISTAS NA UNIVERSIDADE FEDERAL DE VIÇOSA - CAMPUS RIO PARANAÍBA: DAS DIRETRIZES DO FORPROEX ÀS PERCEPÇÕES DE ATORES ENVOLVIDOS \\ DOI: http://dx.doi.org/10.5007/1983-4535.2018v11n1p116}

Neste sentido, para análise das percepções mensuradas em escala likert foi utilizado o software SPSS19.0 ® para tabulação de dados e obtenção de resultados. Optou-se pelo teste estatístico T (Student). Segundo Dancey e Reidy (2007) este teste é utilizado quando se tem duas condições. Especificamente utilizou-se o teste t para amostras independentes, que segundo os autores é indicado quando os participantes tomam parte em apenas uma de duas condições ou quando se trata de um delineamento independente, como é o caso deste trabalho com categorias distintas: empresários e docentes.

Tal teste, objetiva comparar as médias populacionais. Segundo Malhotra (2009) a média seria o valor médio ou medida usada para tendência central ou centro de uma distribuição, serve também para estimar uma média quando os dados foram coletados com uma escala de intervalo e geralmente estes dados apontam alguma tendência central, com respostas distribuídas em torno da média. Foi verificado também o desvio padrão, que segundo os mesmos serve para auxiliar a entender quão agrupada ou espalhada a distribuição está em torno da média.

\section{RESULTADOS E DISCUSSÃO}

\subsection{CARACTERIZAÇÃO DOS ATORES ENVOLVIDOS NA PESQUISA}

Em relação aos 20 empresários entrevistados, observa-se que 12 (60\%) deles tem sua empresa atuando no mercado de Rio Paranaíba há mais de seis anos. O setor de atuação que apresentou maior percentual foi o comércio $12(60 \%)$, boa parte deles já atuam como gestor há mais de 6 anos $10(50 \%), 4(20 \%)$ atuam de 3 a 4 anos, $3(15 \%)$ atuam de 1 a 2 anos e outros $3(15 \%)$ de 5 a 6 anos. Em sua maioria 14 (70\%) são do sexo masculino e os demais 6 (30\%) feminino, a faixa etária que prevalece é a de 31 a 40 anos com 9 (45\%), seguida da de 21 e 30 anos que foram $6(30 \%)$. Em relação à formação 7 (35\%) tem ensino superior completo, 5 (25\%) tem ensino médio e 8 (40\%) tem ensino superior incompleto.

Em relação aos professores do ICHS da UFV- CRP o que se pode inferir é que a maioria 5 (33,3\%) é professor na instituição de 4 a 5 anos, em relação ao sexo 8 (53,3\%) são masculino e $7(46,7 \%)$ feminino. No tocante à faixa etária $10(66,7 \%)$ estão entre 31 e 40 anos, a maior parte $11(73,3 \%)$ participa de 1 a 3 atividades de extensão por ano, sendo que os projetos $5(33,2 \%)$ é a forma que mais se destaca, portanto, a forma de participação mais representativa foi como coordenador $6(40 \%)$. 


\subsection{CARACTERIZAÇÃO DAS ATIVIDADES DE EXTENSÃO A PARTIR DAS DIRETRIZES PATUADAS PELO FORPROEX (2012)}

Quadro 3 Média e Desvio Padrão relacionados às afirmativas propostas nos questionários

\begin{tabular}{|c|c|c|c|c|}
\hline & GRUPO & $\mathbf{N}$ & MÉDIA & $\begin{array}{c}\text { DESVIO PADRÃO } \\
\text { AMOSTRAL }\end{array}$ \\
\hline \multirow{2}{*}{ Questão 1} & Empresarios & 20 & 4,95 & 1,504 \\
\hline & Docentes & 15 & 5,33 & 1,447 \\
\hline \multirow[t]{2}{*}{ Questão 2} & Empresarios & 20 & 4,55 & 1,538 \\
\hline & Docentes & 15 & 5,20 & 1,568 \\
\hline \multirow[t]{2}{*}{ Questão 3} & Empresarios & 20 & 5,45 & 1,701 \\
\hline & Docentes & 15 & 5,13 & 1,302 \\
\hline \multirow[t]{2}{*}{ Questão 4} & Empresarios & 20 & 4,25 & 1,517 \\
\hline & Docentes & 15 & 4,87 & 1,685 \\
\hline \multirow[t]{2}{*}{ Questão 5} & Empresarios & 20 & 6,25 & ,639 \\
\hline & Docentes & 15 & 5,40 & 1,404 \\
\hline \multirow[t]{2}{*}{ Questão 6} & Empresarios & 20 & 6,25 & 1,118 \\
\hline & Docentes & 15 & 5,87 & 1,246 \\
\hline \multirow[t]{2}{*}{ Questão 7} & Empresarios & 20 & 5,60 & 1,501 \\
\hline & Docentes & 15 & 5,33 & 1,234 \\
\hline \multirow[t]{2}{*}{ Questão 8} & Empresarios & 20 & 5,05 & 1,191 \\
\hline & Docentes & 15 & 5,13 & 1,125 \\
\hline \multirow[t]{2}{*}{ Questão 9} & Empresarios & 20 & 4,05 & 1,791 \\
\hline & Docentes & 15 & 4,80 & 1,082 \\
\hline \multirow[t]{2}{*}{ Questão 10} & Empresarios & 20 & 5,40 & 1,501 \\
\hline & Docentes & 15 & 5,40 & ,986 \\
\hline
\end{tabular}

Fonte: Dados da Pesquisa. Rio Paranaíba, MG (2015).

No que tange à questão 1 , a maior pontuação atribuída pelos professores é coerente com o que afirmaram ao esclarecer que os mesmos têm tentado e feito aquilo que lhes concerne no sentido destas atividades, conforme fala de um dos docentes:

\footnotetext{
"Muitos deles têm se esforçado e se dedicado nesse sentido." (D6)
}

Da mesma forma, a menor pontuação colocada pelos empresários se confirma observando-se um dos discursos:

\footnotetext{
"Olha eu acho que ainda tem muito a desejar, precisava de maior participação da universidade na comunidade, faltam cursos, projetos, poderia haver maior interação com as empresas de Rio Paranaíba." (E 4)
}

Para a questão 2, as pontuações obtidas para os grupos podem ser esclarecidas ao se observar os trechos de um empresário, que acusa falha nas metodologias da Universidade e de 


\title{
AVALIANDO AS PRÁTICAS EXTENSIONISTAS NA UNIVERSIDADE FEDERAL DE VIÇOSA - CAMPUS RIO PARANAÍBA: DAS DIRETRIZES DO FORPROEX ÀS PERCEPÇÕES DE ATORES ENVOLVIDOS DOI: http://dx.doi.org/10.5007/1983-4535.2018v11n1p116
}

um docente que, apesar de concordar parcialmente, também faz a mesma indicação, respectivamente:

\begin{abstract}
“As metodologias que a faculdade aplica não conseguem aderência dos empresários, acho que a universidade deve passar a conversar, ter uma linguagem diferente e acessível com o empresariado." (E 4)
\end{abstract}

"Não tenho muito conhecimento dos cursos ofertados, deveria ser mais divulgado." (D 10)

Para a questão 3, a avaliação aponta que os empresários conseguem enxergar com maior clareza este envolvimento de diferentes profissionais, áreas do conhecimento e ganhos múltiplos nas atividades de extensão das quais participaram do que os docentes. Em conformidade a este resultado, segue abaixo o discurso de um dos empresários:

\begin{abstract}
"Já participei de atividades e com certeza foram importantes porque mesmo que a gente não consiga implantar tudo que a gente aprende, abre a sua visão, te mostra muitas coisas que às vezes você não percebia, desperta sua atenção. A gente vê o quanto as pessoas crescem, amadurecem e aprendem nestas atividades de extensão." (E 8)
\end{abstract}

Para a questão 4, a avaliação mostra que os empresários percebem de maneira distinta o alcance dos diversos setores da comunidade em relação aos docentes. Corrobora com este resultado a citação do empresário a seguir:

"Com certeza a extensão é importante, apesar de que infelizmente vejo mais interface com outros cursos. A administração e contabilidade deixam muito a desejar, até por serem mais teóricas e não ter tanta coisa prática como os demais tem, como uma engenharia, nutrição, agronomia, então fica a desejar." (E 8)

Para a questão 5, as medias registradas indicam que é mais perceptível para os empresários que as atividades de extensão desenvolvidas pela Universidade vinculam-se ao ensino e à pesquisa.

“[...] como a faculdade faz experimentos, tem laboratórios, principalmente para a área agrícola, traz experimentos que funcionaram e podem estar sendo passados para agricultores aqui da cidade. [...] então como te disse traz conhecimentos que vão beneficiar tanto os alunos daqui quanto os que vêm de fora. Isso vem para mostrar estas novas experiências e ver que também está sendo um resultado positivo no geral." (E 12)

“O ensino tem uma relevância social ampla, mas no local Universidade é restrita aos alunos. A pesquisa tem relevância concretizada pelos pares e encontros periódicos acadêmicos. A extensão, bem feita, consegue atingir um público maior, assim, sua relevância se torna maior. O campus possui uma ampla perspectiva de crescimento para a oferta de cursos de extensão, no entanto, tem que superar a resistência da 


\section{AVALIANDO AS PRÁTICAS EXTENSIONISTAS NA UNIVERSIDADE FEDERAL DE VIÇOSA - CAMPUS RIO PARANAÍBA: DAS DIRETRIZES DO FORPROEX ÀS PERCEPÇÕES DE ATORES ENVOLVIDOS \\ DOI: http://dx.doi.org/10.5007/1983-4535.2018v11n1p116}

população de Rio Paranaíba. Muitos ainda desconhecem a importância da Universidade e os benefícios que poderiam ser obtidos." (D7)

Para a questão 6, as médias revelam maior concordância dos empresários para esta questão.

"Um outro aspecto que envolve a extensão é a formação do aluno, seja com práticas em sua área de especialização, seja com aprendizado sobre cidadania e cooperação.” (D 4)

“A prestação de serviços na questão do estágio é muito importante, na verdade o mais importante a meu ver, porque o conhecimento adquirido na universidade passa para o comércio, para os empresários. São dois gumes: um está aprendendo a trabalhar para ir para o mercado de trabalho e o outro está aprendendo com o estagiário também que está com as ideias frescas para passar o conhecimento.” (E 14)

Para a questão 7, a avaliação leva a inferir que nas atividades das quais participaram, os empresários visualizaram com maior nitidez a figura dos orientadores e dos estudantes, os quais foram claros naquilo que se propuseram a fazer na atividade. $O$ depoimento do empresário que segue atesta:

“[...] tenho acompanhado bastante o trabalho feito através tanto de professores como novas ideias, a questão do acompanhamento dos alunos que fazem parte dos cursos dentro desta área agrícola. [...] o pessoal está vendo que realmente a tendência para novas tecnologias, a questão do aprendizado que este pessoal da universidade tem trago junto com eles, a bagagem profissional deles, com mudanças tem trago muitos benefícios e juntamente os alunos nesta propriedade é que coordenam o projeto. Ou seja, foi um projeto lançado pelos professores mas a continuidade dele está nas mãos dos alunos. Eu acho particularmente bastante interessante." (E 7)

Para a questão 8 , tanto empresários quanto docentes concordam parcialmente, porém os primeiros percebem menos esta atuação, conforme aponta o trecho:

"Pode-se ter uma maior participação dos alunos dentro da própria comunidade, então eu vejo este distanciamento.” (E 6)

Para a questão 9, os empresários têm uma percepção menor de que as atividades estão sendo de fato representativas. O docente D 14 afirma que muitas vezes a falta de efetividade das ações pode emergir por parte dos docentes, conforme observa-se:

"Devido à própria comunidade acadêmica, principalmente dos docentes, que costumam fazer os projetos de acordo com os próprios interesses, e não com a "real" necessidade da comunidade. Embora a "real necessidade" seja um tanto quanto idealismo, pois muitas vezes temos que "criar" a tal necessidade para desenvolver o projeto. [...] Acredito que tais limitações vão sendo vencidas na medida em que os projetos já em andamento comecem a apresentar seus resultados, e que os docentes e discentes não desanimem com o alcance de metas parciais ou até bem diferentes das planejadas". (D 14) 
Por fim, para a questão 10, os docentes e empresários foram unânimes em suas médias, aproximando-se do nível concordo. Reforçam estes resultados, os depoimentos abaixo acerca das mudanças na Universidade e as expectativas, o primeiro de um docente e o segundo de um empresário:

\footnotetext{
“A estruturação da Diretoria de Extensão no CRP foi um passo importante para o fortalecimento dessa área no Campus. Acredito em um futuro promissor para a extensão no CRP. Entretanto, isso depende de respaldo institucional, da UFV, de órgãos de fomento, da comunidade acadêmica e da comunidade local.” (D 11)
}

"Em vista do que era antes da faculdade entrar e agora já melhorou bastante.” (E 3)

Em complemento à análise e para compararmos de fato as diferenças de médias, procedeu-se o teste de hipóteses, assumindo-se H1 como "Existe diferença significativa entre as médias na percepção de empresários e docentes acerca das práticas de extensão". Estabeleceu-se o intervalo de confiança de $95 \%$ e $\alpha=0,05$. Para efeitos de análise considerase que se o Sig. (2-tailed) ou P-valor for $\leq \alpha(0,05)$ então se rejeita a hipótese $\mathrm{H} 0$, caso este valor seja $\geq \alpha(0,05)$ então aceita-se a hipótese $\mathrm{H} 0$.

O quadro abaixo nos descreve os resultados obtidos com as duas populações:

Quadro 4 Teste t aplicado aos docentes e empresários

\begin{tabular}{|c|c|c|c|c|c|c|c|c|c|}
\hline \multicolumn{10}{|c|}{ TESTE T PARA AMOSTRAS INDEPENDENTES } \\
\hline & \multicolumn{2}{|c|}{$\begin{array}{l}\text { Teste Levene } \\
\text { para } \\
\text { Igualdade de } \\
\text { Variância }\end{array}$} & & & & & & & \\
\hline & \multirow[t]{2}{*}{$\mathrm{F}$} & \multirow[t]{2}{*}{ Sig. } & \multirow[t]{2}{*}{$\mathrm{T}$} & \multirow{2}{*}{$\begin{array}{l}\text { Graus } \\
\text { Liber } \\
\text { dade }\end{array}$} & \multirow{2}{*}{$\begin{array}{l}\text { Sig. (2- } \\
\text { tailed) } \\
\text { ou P- } \\
\text { Valor }\end{array}$} & \multirow[t]{2}{*}{$\begin{array}{l}\text { Diferença } \\
\text { de Médias }\end{array}$} & \multirow{2}{*}{$\begin{array}{l}\text { Erro } \\
\text { Padrão da } \\
\text { Dif. das } \\
\text { Médias }\end{array}$} & \multicolumn{2}{|c|}{$\begin{array}{lrr}95 & \% & \text { Int. } \\
\text { Confiança } & \\
\end{array}$} \\
\hline & & & & & & & & $\begin{array}{l}\text { Inferio } \\
\mathrm{r}\end{array}$ & Superior \\
\hline Questão 1 & 077 & ,783 &,- 758 & 33 & ,454 &,- 383 & 506 & $-1,412$ & 645 \\
\hline Questão 2 & ,107 &, 746 & $-1,227$ & 33 & 228 &,- 650 &, 530 & $-1,728$ & ,428 \\
\hline Questão 3 & 1,081 & ,306 & 600 & 33 &, 552 & 317 &, 527 &,- 756 & 1,390 \\
\hline Questão 4 & ,132 & ,718 & $-1,135$ & 33 & 265 &,- 617 & ,543 & $-1,722$ & ,489 \\
\hline Questão 5 & 9,086 & 005 & 2,404 & 33 & ,022 &, 850 & ,354 & ,131 & 1,569 \\
\hline Questão 6 & 1,177 &, 286 & ,956 & 33 &, 346 & ,383 & ,401 &,- 433 & 1,199 \\
\hline Questão 7 &, 527 & ,473 & ,560 & 33 & ,579 & ,267 & ,476 &,- 702 & 1,235 \\
\hline Questão 8 & ,014 & ,906 &,- 210 & 33 &, 835 &,- 083 & ,397 &,- 892 & ,725 \\
\hline Questão 9 & 7,846 & 008 & $-1,434$ & 33 & ,161 &,- 750 &, 523 & $-1,814$ & ,314 \\
\hline Questão 10 & 1,334 & 256 & .000 & 33 & 1,000 & .000 & .447 &,- 908 & ,908 \\
\hline
\end{tabular}

Fonte: Dados da Pesquisa. Rio Paranaíba, MG (2015). 
Assim sendo, observa-se que em relação ao P-Valor ou Sig. (2-tailed) apenas a questão 5 apresentou $\alpha<0,05$, sendo no valor de 0,022 . Portanto no quesito percepção quanto à vinculação das atividades de extensão, às atividades de ensino e pesquisa rejeita-se a hipótese $\mathrm{H} 0$ de que não há diferenças significativas entre as médias. No tocante às demais questões, todas apresentaram $\alpha>0,05$, por isso aceita-se a hipótese de que não houveram diferenças significativas nas percepções de docentes e empresários através das médias encontradas. O quadro 5, a seguir, descreve a média para cada diretriz estudada:

Quadro 5 Média encontrada pelos respondentes para cada diretriz

\begin{tabular}{|c|c|c|}
\hline & $\begin{array}{c}\text { EMPRESÁRIO } \\
\text { S }\end{array}$ & DOCENTES \\
\hline DIRETRIZES PACTUADAS PELO FORPROEX (2012) & $\begin{array}{c}\text { MÉDIA } \\
\text { DIRETRIZ }\end{array}$ & $\begin{array}{c}\text { MÉDIA } \\
\text { DIRETRIZ }\end{array}$ \\
\hline INTERAÇÃO DIALÓGICA & 4,75 & 5,27 \\
\hline $\begin{array}{c}\text { INTERDISCIPLINARIDADE E } \\
\text { INTERPROFISSIONALIDADE }\end{array}$ & 4,85 & 5,00 \\
\hline $\begin{array}{c}\text { ENTENSS̃O } \\
\text { EXOCINOSESQUISA- }\end{array}$ & 6,25 & 5,63 \\
\hline IMPACTO NA FORMAÇÃO DO ESTUDANTE & 5,32 & 5,23 \\
\hline IMPACTO E TRANSFORMAÇÃO SOCIAL & 4,72 & 5,10 \\
\hline
\end{tabular}

Fonte: Dados da Pesquisa. Rio Paranaíba, MG (2015).

Face ao exposto no Quadro 8, foi possível a elaboração do gráfico que confirma os resultados obtidos acerca da diferença significativa das médias de percepção entre empresários e docentes apenas para a questão 5, que faz alusão à indissociabilidade ensinopesquisa-extensão. Assim sendo, é possível observar que os empresários respondentes conseguem visualizar com maior nitidez nas atividades de extensão promovidas pela Universidade à vinculação ao Ensino (no que tange à formação de pessoas) e da Pesquisa (geração de conhecimentos), conforme evidencia-se: 
Gráfico 1 Percepção sobre as diretrizes do FORPROEX nas atividades de extensão da UFVCRP.

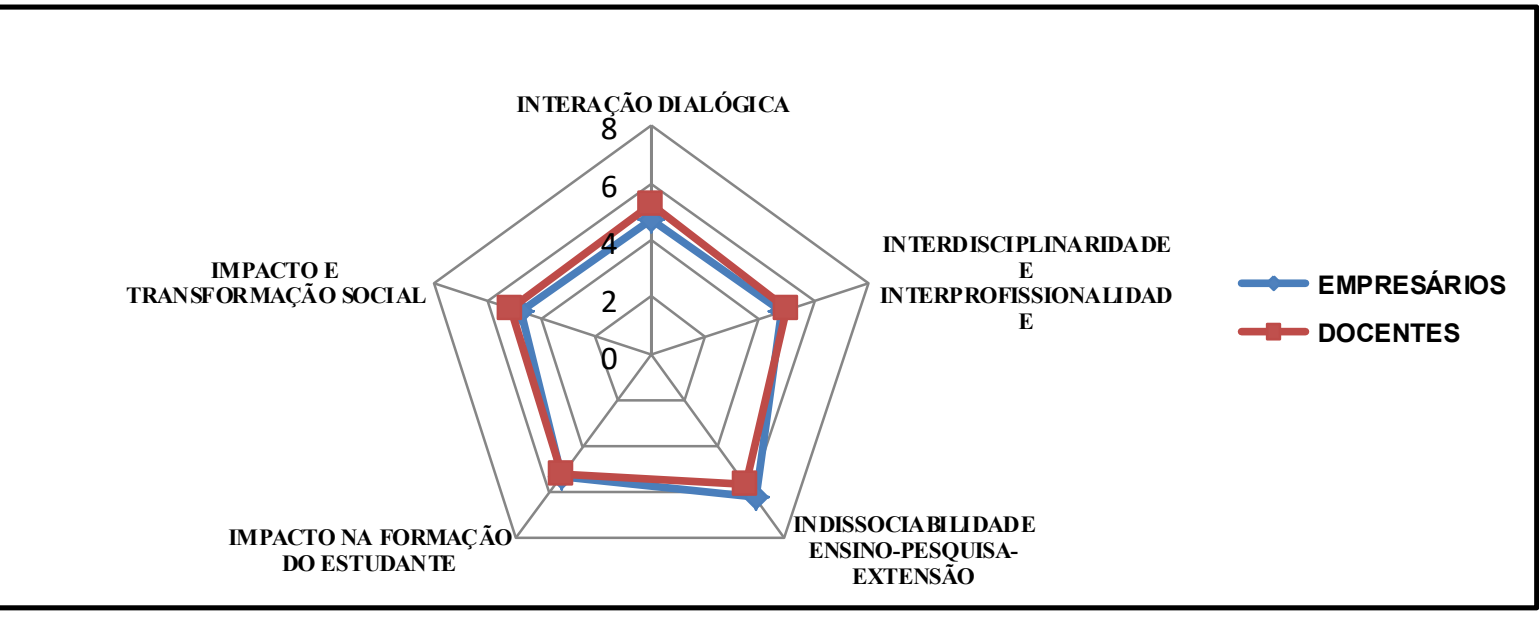

Neste sentido, é possível perceber que as atividades de extensão promovidas pela Universidade têm alcançado pontuação que fique entre 4,72 (menor média) e 6,25 (maior média) no que tange a uma escala likert de 7 pontos.

Portanto, a diretriz que menos pontuou em média foi à que se refere ao impacto e transformação social, apontada pelos empresários, os quais afirmam não conseguir ter esta percepção de efetividade através destas atividades na resolução de problemas e gargalos localizados na comunidade local. Em contrapartida, a que mais pontuou foi a média, também de empresários, vinculada à indissociabilidade ensino-pesquisa-extensão, nas quais os mesmos inferem perceber formação de pessoas e geração de conhecimento.

No que tange à diretriz da interação dialógica, fica evidente que os empresários obtiveram média menor que a dos docentes, alcançando 4,75 para os primeiros citados e 5,27 para os segundos. Portanto, é possível ainda notar que neste quesito a Universidade tem sido percebida como produtora de um conhecimento que tende à via de mão única, aonde a mesma vai até a comunidade levar algo da qual é especialista e esta comunidade apenas recebe este conhecimento, não obtendo a postura de diálogo e interação.

\section{CONSIDERAÇÕES FINAIS}

Neste sentido, é possível perceber que as atividades de extensão promovidas pela Universidade têm alcançado pontuação que fique entre 4,72 (menor média) e 6,25 (maior média) no que tange a uma escala likert de 7 pontos. 
Portanto, a diretriz que menos pontuou em média foi à que se refere ao impacto e transformação social, apontada pelos empresários, os quais afirmam não conseguir ter esta percepção de efetividade através destas atividades na resolução de problemas e gargalos localizados na comunidade local. Em contrapartida, a que mais pontuou foi a média, também de empresários, vinculada à indissociabilidade ensino-pesquisa-extensão, nas quais os mesmos inferem perceber formação de pessoas e geração de conhecimento.

No que tange à diretriz da interação dialógica, fica evidente que os empresários obtiveram média menor que a dos docentes, alcançando 4,75 para os primeiros citados e 5,27 para os segundos. Portanto, é possível ainda notar que neste quesito a Universidade tem sido percebida como produtora de um conhecimento que tende à via de mão única, aonde a mesma vai até a comunidade levar algo da qual é especialista e esta comunidade apenas recebe este conhecimento, não obtendo a postura de diálogo e interação.

\section{REFERÊNCIAS}

BARBOSA, V. C. Extensão Universitária: proposição e validação de um instrumento de avaliação da percepção dos discentes. Fumec. Faculdade de Ciências Empresariais. Belo Horizonte, 2012. Disponível em: <http://www.fumec.br/anexos/cursos/mestrado/dissertacoes/ completa/valeska-cristina-barbosa.pdf $>$ Acesso em: 31 maio 2014.

CASTRO, L. M. C. A universidade, a extensão universitária e a produção de conhecimentos emancipadores. In: REUNIÃO ANUAL DA ANPED, 27, Caxambu, 2004. Anais... Caxambu: ANPEd, 2004. Disponível em: < http://27reuniao.anped.org.br/gt11/ t1111.pdf> Acesso em: 31 maio 2014.

CHAUÍ, M. A universidade pública sob nova perspectiva. Universidade de São Paulo, Faculdade de Filosofia, Letras e Ciências Humanas. Revista Brasileira de Educação, n. 24, set/dez.2003. Disponível em $:<$ http://www.scielo.br/pdf/rbedu/n24/n24a02.pdf $>$ Acesso em: 31 maio 2014.

COCCO, R.; NUNES, G. L.; SANTOS, S. A.; KEMPKA, S. B. Política de expansão e interiorização/regionalização do ensino público superior no Brasil: 0 caso da UFSM/Cesnors - uma perspectiva a partir do egresso. In: ANPAE, 2013. Disponível em: $<$ http://www.anpae.org.br/IBERO_AMERICANO_IV/GT2/GT2_Comunicacao/Ricardo_Coc coGT2_integral.pdf.>Acesso em: 08 abr. 2014.

CUNHA, L. M. A. Modelos Rasch e Escalas de Likert e Thurstone na medição de atitudes. 2007. 78 f. Dissertação (Mestrado em Probabilidades e Estatística) - Universidade de Lisboa - Faculdade de Ciências- Departamento de Estatística e Investigação Operacional. Lisboa, Portugal, 2010. Disponível em: < http://repositorio.ul.pt/bitstream/10451/1229/1/ 18914_ULFC072532_TM.pdf> Acesso em: 31 maio 2014. 
DANCEY, C. P.; REIDY, J. Estatística sem matemática para psicologia. Tradução Lorí Viali. 3 ed. Porto Alegre: Artmed, 2007.

FÓRUM DE PRÓ-REITORES DE EXTENSÃO DAS UNIVERSIDADES PÚBLICAS BRASILEIRAS. Política Nacional de Extensão Universitária. Manaus: maio 2012. Disponível em :<http://www.proec.ufpr.br/downloads/extensao/2012/legislacao/Politica\%20 Nacional\%20de\%20Extensao\%20Universitaria\%20maio2012.pdf>. Acesso em: 08 abr. 2014.

FÓRUM DE PRÓ-REITORES DE EXTENSÃO DAS UNIVERSIDADES PÚBLICAS BRASILEIRAS E SESU/ MEC. Plano Nacional de Extensão Universitária. Ed. Atualizada, Brasil 2000/2001. Disponível em: http://www.portal.ufpa.br/docsege/Planonacionalde extensaouniversitaria.pdf . Acesso em: 03 jul. 2014.

FREIRE, P. Extensão ou Comunicação? Tradução de Rosisca Darcy de Oliveira, 8ed. Rio de Janeiro: Paz e Terra, 1985.

.; SHOR, I. Medo e ousadia: o cotidiano do professor. Tradução de Adriana Lopez, revisão técnica de Lólio Lourenço de Oliveira- Rio de Janeiro: Paz e Terra, 1987.

FRIGOTTO, G. A interdisciplinaridade como necessidade e como problema nas ciências sociais. In: JAPIASSU, H. Interdisciplinaridade e patologia do saber. Rio de Janeiro: Imago, 1976.

GOMES, F. P.; ARAÚJO, R. M. Pesquisa Quanti-Qualitativa em Administração: uma visão holística do objeto em estudo. VIII SEMEAD - Seminários em Administração. FEA/USP. Disponível em: <http://www.ead.fea.usp.br/Semead/8semead/resultado/ trabalhosPDF/152.

pdf>. Acesso em: 12 maio 2014.

IBGE, Instituto Brasileiro de Geografia e Estatística. Estatísticas do cadastro central de empresas -2012. Disponível em: <http://cidades.ibge.gov.br/xtras/temas.php? lang=\&codmun $=315550 \&$ idtema $=127 \&$ search $=$ minas-gerais $\mid$ rio-paranaiba|estatisticas-do-cadastro-centralde-empresas-2012>. Acesso em: 08 de jun. 2014.

I ENCONTRO DE PRÓ- REITORES DE EXTENSÃO DAS UNIVERSIDADES PÚBLICAS BRASILEIRAS, 1987, Brasília. Conceito de extensão, institucionalização e financiamento. In: NOGUEIRA, M. D. P. (org). Extensão Universitária: diretrizes conceituais e políticas - Documentos básicos do Fórum Nacional de Pró-Reitores de Extensão das Universidades Públicas Brasileiras 1987 - 2000. Belo Horizonte: PROEX/UFMG; o Fórum, 2000. Disponível em: <http://www.renex.org.br/documentos/ Encontro-Nacional/1987-I-Encontro-Nacional-do-FORPROEX.pdf $>$. Acesso em: 08 abr. 2014.

JEZINE, E. As Práticas Curriculares e a Extensão Universitária. Anais.. .Belo Horizonte, set./2004. Disponível em: <https://www.ufmg.br/congrext/Gestao/Gestao12.pdf >. Acesso em: 03 jul. 2014. 
LEFF, E. Complexidade, interdisciplinaridade e saber ambiental. In: Interdisciplinaridade em ciências ambientais. São Paulo: Signus, 2000.

MALHOTRA, N. K. Introdução à pesquisa de Marketing. Tradução Robert Brian Taylor. São Paulo: Pearson Prentice Hall, 2009.

MOITA, F. M. G. S. C.; ANDRADE, F. C. B. Ensino-Pesquisa-Extensão: um exercício de indissociabilidade na pós- graduação. Revista Brasileira de Educação, v.14, n.41, maio/ago. 2009. Disponível em : $<\mathrm{http}: / / w w w . s c i e l o . b r / p d f / r b e d u / v 14 n 41 / v 14 n 41 a 06 . p d f>$ Acesso em: 31 maio 2014.

NOGUEIRA, M. D. P. (Org.) Extensão Universitária: diretrizes conceituais e políticas. Belo Horizonte: PROEX/UFMG; O Fórum, 2000.

NOGUEIRA, M. D. P. Políticas de Extensão Universitária Brasileira. Belo Horizonte: Editora UFMG, 2005.

NUNES, A. L. P. F. ; SILVA, M. B. C. A extensão universitária no ensino superior e a sociedade. Revista Mal-Estar e Sociedade. Barbacena: Ano IV, n.7, p. 119-133, jul./dez./2011. Disponível em :<http://www.uemg.br/openjournal/index.php/malestar/ article/view/60>. Acesso em: 08 abr. 2014.

RICHARDSON, R. J. Pesquisa social: métodos e técnicas. 3. ed. São Paulo: Atlas, 1999. $334 p$.

ROCHA, R. M. G. A Construção do Conceito de Extensão universitária na America Latina. In. FARIA, D. S. de (org). Construção Conceitual da Extensão na America Latina. Brasilia. Editora UNB. 2001

SERRANO, R. M. S. M. Conceitos de extensão universitária: um diálogo com Paulo Freire. PRAC (Pró Reitoria de Extensão e Assuntos Comunitários), UFPB. Disponível em $:<$ http://www.prac.ufpb.br/copac/extelar/atividades/discussao/artigos/conceitos_de_extensao_ universitaria.pdf> Acesso em: 31 maio 2014.

THIOLLENT, M. Construção do conhecimento e metodologia da extensão. I CONGRESSO BRASILEIRO DE EXTENSÃO UNIVERSITÁRIA, João Pessoa, 2002. Disponível

em: $<$ http://www.sistemas.ufrn.br/shared/verArquivo?idArquivo $=689391 \& \mathrm{key}=\mathrm{c} 134 \mathrm{fc} 26 \mathrm{a} 973$ d27dd65f00b19bbf6edb >. Acesso em: 07 jul. 2014.

UNIVERSIDADE FEDERAL DE VIÇOSA. Estatuto da Universidade Federal de Viçosa. Viçosa, 1999. Aprovado pelo Conselho Universitário, Portaria n. 768 do Ministério da Educação e publicado no Diário Oficial em 18 de maio de 1999. Disponível em: $<$ http://www.ufv.br/soc/files/pag/estatuto.htm>. Acesso em: 08 abril 2014.

VERGARA, S. C. Projetos e relatórios de pesquisa em Administração. 7. ed. São Paulo: Atlas, 2006. 